\title{
Offset Contracts as an Insurance Device in Building the National Security
}

\author{
Vesa Kanniainen \\ University of Helsinki, HECER, CESifo, and \\ Finnish National Defence University \\ and \\ Juha-Matti Lehtonen \\ Finnish National Defence University
}

Discussion Paper No. 412

April 2017

ISSN 1795-0562

HECER - Helsinki Center of Economic Research, P.O. Box 17 (Arkadiankatu 7), FI-00014 University of Helsinki, FINLAND,

Tel +358-2941-28780, E-mail info-hecer@helsinki.fi, Internet www.hecer.fi 


\title{
Offset Contracts as an Insurance Device in Building the National Security*
}

\begin{abstract}
A dynamic multi-stage decision-theoretic approach is introduced to establish the optimal offset and its incidence, the contract price arising from bargaining, and the scale of the acquisition. A new rationale is suggested for offsets in terms of their role as an insurance devise. Results are derived for the pricing of delivery contracts subject to offset claims and their national security implications. It is shown that the national security is strictly convex in the offset transaction. As to the incidence of the offset, the offset claim is shown to be capitalised in the delivery price. The bargaining price is shown to depend on the value of the product to be delivered for the national security, the relative negotiation power of the contracting partners and the social cost of public funds. The analysis highlights the expectation effects of offsets on the bargaining price and the scale of delivery. The results aid in explaining why offsets are widely used in procurement contracts for defence materiel. As they contribute to the national security, they should be allowed to survive and not be denied under competition laws.
\end{abstract}

JEL Classification: H12, H56

Keywords: offsets, national security, defence materiel, insurance

Vesa Kanniainen

Department of Political and Economic Studies

University of Helsinki

P.O. Box 17 (Arkadiankatu 7)

FI-00014 University of Helsinki

FINLAND

e-mail: vesa.kanniainen@helsinki.fi
Juha-Matti Lehtonen

Finnish National Defence University

P.O. Box 7

FI-00861 Helsinki

FINLAND

e-mail: juha-matti.lehtonen@mil.fi

* The authors are indebted to Tapio Palokangas for helpful comments. 


\section{Introduction}

International trade in defence materiel is large. Most countries do not produce all their defence materiel by themselves. Instead, they meet some of their needs by engaging in trade in such material with other countries. For example, defence is among Europe's main sectors of industry, fuelling innovation and growth of the wider EU economy. The European Commission has stated that, with a turnover of 96 billion euro in 2012 alone, it is a major industrial sector, generating innovations and centred on high-end engineering and technologies. ${ }^{1}$

As explicated by Taylor (2012), the production of defence material is characterised by high start-up costs and substantial research and development (R\&D) investments. Such regularities point to the exchange as taking place in conditions that may markedly deviate from perfectly competitive markets and as subject to bargaining that generates economic rents. Taylor points to high transactions costs, incomplete and asymmetric information, and bounded rationality as characteristic of this exchange setting. High fixed costs in production may lead to increasing returns, thereby creating incentives to augment the producer's domestic market with export sales. Often, especially in the case of the aerospace industry, the contracts are of extensive scale, and the materiel represents public goods and is tax-financed by the purchasing government. The products in the markets are imperfect substitutes, and the buyer has to match them with the

\footnotetext{
${ }^{1}$ European Commission (2013).
} 
qualities it is hoping to acquire. These products are typically highly complex and consist of thousands of parts (Hall and Markowski, 1994).

'Offset' refers to any type of non-monetary compensation that a procuring government requires an exporting firm to provide as a condition of the sale, and it generally commits the exporting firm to spend a certain percentage of the value of the sale in the procuring country (Petersen, 2011). An offset agreement is a contract between a purchasing government and a foreign supplier. The latter is encouraged or even required to provide additional benefits for the purchasing government's economy, beyond the base transaction (Taylor, 2012). The term 'offset', or sometimes 'industrial participation', is used in connection with military items procured by governments: one factor in this is that, since Article IV.6 of the World Trade Organization (W.T.O.) Agreement on Government Procurement forbids the use of offsets in general while exempting armaments, 'offset' may be deemed exclusive to defence purchases.

Offsets may take various forms; according to B.I.S. (2016), 'offsets in defence trade include a range of industrial compensation arrangements required by foreign governments'. They are commonly divided between direct and indirect, where a direct offset is connected to the item purchased and an indirect offset is not, and between military and non-military (i.e. civilian) offsets. The compensation requirement may take various forms; the U.S. applies the following categories for offset transactions: co-production, technology transfer, subcontracting, credit assistance, training, licensed production, investment, purchases, and other (B.I.S., 2016). Moreover, governments that demand offsets may differ in the amount of offset required and in the multipliers employed in calculation of the offset value of a specific transaction (e.g. B.I.S., 2016). 
Offsets are extensively used in trading in defence material. According to Ungaro (2013), offsets between 2005 and 2016 were projected cumulatively to amount to $\$ 500$ billion internationally. The view that emerges from the existing literature is that offsets represent marketing devices as nonstandard contracting in international procurement amidst concentrated market structures and are particularly valuable in generating efficiency gains though they represent deviations from free trade. ${ }^{2}$ This is even though the European defence procurement directive (2009/81) and U.S. offset policy, echoing the W.T.O. view, are against offsets. Yet in 1993-2008, 48 U.S. firms signed, in all, 677 offset agreements, worth $\$ 68.93$ billion. In 2008, 14 companies entered into offset agreements, with 52 contracts, in support of $\$ 6.09$ billion in export sales. For the last 15 years, the compensation ratio for U.S. firms that signed offset agreements is 70.96 per cent. $^{3}$

In a study commissioned by the European Defence Agency (E.D.A.), Eriksson et al. (2007) estimated that there is a 40/60 split between direct and indirect offsets in E.D.A. participating member states (pMS) but were unable to estimate the offset transactions' value in relation to contract value. In the U.S.A., the 20th offset report to Congress (B.I.S., 2016) cited a $\$ 171$ billion contract value covering offset clauses in 1993-2014, while the offset transaction value in the same period was $\$ 71$ billion. As direct offsets accounted for 39,4 per cent of the actual value of the reported offset transactions in 1993-2014 (B.I.S., 2016), one may conclude that the actual value of direct-offset transactions came to 16 per cent of the contract value during that time for U.S. military exports with offsets.

In light of the fact that the international defence trade is very large and that offset contracts are very commonplace in connection with large deliveries, the previous analytic literature on offsets

\footnotetext{
${ }^{2}$ Taylor (2012) refers to an audit performed by PriceWaterhouseCoopers showing that the net benefits of offset agreements signed by the government of the Netherlands were positive. ${ }^{3}$ These figures were released by the U.S. Department of Commerce (see Taylor, 2012).
} 
is surprisingly limited. Many fundamental economic questions surrounding offsets have eluded analytic decision-theoretic and bargaining-theoretic research. Firstly, why are offset requirements overwhelmingly dominant in contracts for delivery of defence materiel, and why do they survive? Secondly, how large an offset claim is optimal for the acquiring country to impose on its trade? Thirdly, what is the incidence of offsets, given that there can be no 'free lunch' in creating insurance? In addition, how is the price of the delivery contract determined in light of the acquiring country's demands for an offset? Fifthly, how does the offset requirement interact with the scale of the delivery contract? Finally, what effect does the delivery contract being subject to the offset have on the acquiring country's national security?

In this paper, we suggest that the main economic benefit of a direct-offset transaction arises from the insurance it provides against the risk of a future contingency; a market for insurance against an adverse contingency may not exist. ${ }^{4}$ The paper introduces an alternative - and new - view of the economics of offset requirements imposed by a purchasing country, considering them from the angle of their impact on the national security. According to the above-mentioned directive (2009/81/EC), any offsets within the E.U. must be based on national security, because exemptions from that directive may be made only under Article 346 T.F.E.U. However, the legal concept of national security is not defined clearly in Article 346; it leaves open how offset practices may be related to national security. Nations differ in the objectives they pursue through offsets. Erikson et al. (2006) found that medium-sized countries that primarily export are interested in developing the national-defence technological and industrial base (D.T.I.B.) through mainly indirect offsets in technology transfer and defence exports while mainly

\footnotetext{
${ }^{4}$ Large exporting countries (such as the United States and France) do not need offsets, since they strive for self-sufficiency and complete independence. For medium-sized countries with sizeable exports (e.g. Italy and the Netherlands), offsets can be desirable for strengthening the country's industrial base. In countries that are members of an alliance (such as Denmark or Norway), offsets may lead to the possibility of delivering components, thereby strengthening the interdependence within the alliance.
} 
importing countries opt for direct offsets. The latter can enhance national security by sustaining national D.T.I.B. capability for equipment maintenance, thereby ensuring equipment availability. One concrete example is that complex defence equipment requires significant training, maintenance, and servicing after acquisition if it is to be able to operate properly. In his case study of the Finnish F-18 deal, Korhonen (2011) explains how direct offset for such operations as assembly and testing aids with maintenance throughout the service life. He concludes that it is especially beneficial in terms of knowledge and skill development if the assembly and maintenance are performed by the same party. Offsets represent the key device for such aims.

In fact, the mechanisms by which offsets enhance the national security are both direct and indirect. The possibility of assembling the aircraft domestically provides the valuable capability of servicing those fighters domestically too. It is widely recognised that high-tech, sophisticated modern defence instruments require periodic servicing and that, hence, many of them are incapable of operating at any given time. ${ }^{5}$ An extreme example is the B-2 Bomber, which a Government Accountability Office report (G.A.O., 1997) described as requiring 124 maintenance hours per flight hour, with an ultimate goal at the time of reducing this figure to 50 per flight hour. Clearly, therefore, the risk of not having sufficient defence equipment functional and operative at short notice is high. The necessary servicing involves installing spare parts etc. and having competent personnel on hand, the required tools and testing devices,

\footnotetext{
${ }^{5}$ It was reported in a Der Spiegel article of 20 December 2017 that, for example, only eight of the 109 Eurofighters in the German army's equipment base are available for flying, seven of the 67 transport helicopters and five of the 33 NH90 helicopters are in operational condition, and 21 of the 56 transport aeroplanes are in sufficiently good condition for operation. Of course, such cases are not limited to the German army.
} 
and updated programs available to facilitate maintenance and repairs. The risk of not having the necessary servicing available when needed from the delivering country is non-trivial.

However, there is more than a direct impact of offsets on the national security. They also enhance the industrial strength of the acquiring country. This, in turn, has a further spillover, i.e. indirect effect on the national security, since the technology transfer strengthens the operational capability of the economy. Such a vision is analysed in the economic model world presented below, suggesting that the offsets do not represent a free lunch. This vision stands in sharp contrast to that of Furter (2014).

The national social opportunity cost of defence materiel is large in terms of the national budget. The approach taken here differs from that followed in prior literature in that the current paper introduces a three-stage decision-theoretic model to examine offsets. In the model world of the current paper, the acquiring country firstly decides on its offset requirement. After this, it negotiates with the delivering country on the price of the delivery. Finally, the acquiring country decides on how many units of the defence materiel it is going to buy.

\section{Offset practices and the legal background - an overview of the literature}

Although the descriptive literature is large, analytic economic work on offsets is limited. There are only a few exceptions. ${ }^{6}$ Mirus and Yeung (1986) suggest that in many circumstances an

\footnotetext{
${ }^{6}$ There is some empirical and analytical work (Kanniainen and Mustonen, 1989; Caves Marin, 1992; Hennart and Anderson, 1993; Yavas Freed, and Vardiabasis 2000) on countertrade which is close to indirect offsets.
} 
offset transaction is a rational response to transaction costs, information asymmetry, moral hazard-agency problems, and other market imperfections. Taylor (2012) elaborates on this proposition in several papers and provides data on the significance of offset transactions in the face of the fact that US and EU policies tend to take a stance against offsets in international trade. Baranowska-Prokop (2009) analyzes a company from a less developed country which plans to acquire an advanced technology embodied in capital goods from a firm in a developed country, where the quality of that technology is unknown to the buyer. It was shown that in the case of substantial uncertainty about the quality of the technology that is being acquired, directoffset transactions can provide insurance against the quality uncertainty and become the preferred form of trading, used instead of market transactions.

The benefits that governments strive to achieve by using offsets can either be purely economic or include national security. On the economic side, Taylor (2003), for example, mentions generation of jobs, technology transfer, increased workloads, promotion of joint ventures, labour training, management services, and safeguarding the base exchange as objectives for offset policy, and similar lists of intended benefits can be found in the work of Petersen (2011), Schoeni (2015), and Martin (1996). Security of supply is intended to ensure the continuing supply of defence materiel and/or services to the armed forces irrespective of external circumstances such as war, international unrest, shifts in alliances, and disruption of the supply chain (Platzgummer, 2015). As for national security, offsets can aid in building the defence industry and improving security of supply (Martin, 1996). A single offset transaction may serve more than one objective; for example, according to Platzgummer (2015), a government may use offsets to receive the technologies needed to enable maintenance of the relevant weapon systems by domestic industry, thereby achieving technology transfer and defence preparedness and probably also increasing employment numbers. An individual country may not pursue all 
possible goals through its offset policies. The offset goals of E.D.A. countries have stressed various aims - for example, export opportunities for defence companies in Italy, technological innovation and marketing support for innovative products in the Netherlands, and the defence industry and its technical capacity in Norway (B.I.S., 2007). Eriksson et al. (2007) grouped pMS broadly into four groups: defence exporters (Germany and France); net exporters (e.g. Italy, Sweden, and the U.K.), which facilitate defence-industry specialisation; major importers (e.g. Finland and Poland) that build a national D.T.I.B. through direct offset; and small countries that strive for economic benefits through civilian indirect offset because of their lack of D.T.I.B.

Many authors question the benefits or, at least, the cost-effectiveness of offset arrangements; see, for example, Brauer and Dunne (2011), Martin (1996), or Taylor (2003). There are no international statistics on offset cost-effectiveness and have been few evaluations of offset policies, with one of the latter being a case study by Castellacci and Fevolden (2014) whose results indicate that offset agreements had a clear role in overcoming entry barriers of three Norwegian defence firms in international markets. Fulfilling offset obligations involves some costs (e.g. management), but no public data or surveys exist on the amount of these, and, for example, according to Fevolden and Tvetbråten (2016), Norwegian defence authorities have prohibited defence contractors from delivering tenders that explicitly state the cost of the offset. However, Eriksson et al. (2007, p. 48) believe that 5-10 per cent is a reasonable range for the direct cost of offset among E.D.A. pMS. In the absence of empirical evidence, one can argue that offsets are uneconomical and irrational, while it is equally plausible that they are a rational response to imperfect markets (Schoeni, 2015). Considering national security goals such as a solid national D.T.I.B., Fevolden and Tvetbråten (2016) deemed the use of offsets a possibly sound strategy for security-related goals such as ensuring security of supply, safeguarding national secrets, and arming the military with suitable defence equipment. 
On the other hand, through Directive 2009/81/EC, the E.U. attempts to reduce offsets in public procurement in the fields of defence and security, in an effort to ensure a more competitive European defence-equipment market (Furter, 2014). Even though the directive does not mention offsets, Commission guidance notes (E.C., 2010) state: 'As restrictive measures infringing primary law, offset requirements can only be justified on the basis of one of the Treaty-based derogations, in particular Article 346 TFEU.' Recent evidence suggests that such intentions appear not to have been realised. The value of procurements awarded under the directives (2009/81 and, for public procurement, 2014/24) is estimated to be 8.5 per cent of total defence-procurement expenditure (E.C., 2016). At E.U. level, there exist no official data on Member States' practices related to offsets-return requirements (E.C., 2016), while B.I.S. (2016) reports that in 2014, U.S. firms entered into new offset agreements with members of the E.D.A. valued at $\$ 1.68$ billion. After a survey involving 71 offset managers, Furter (2014) concluded that, the promulgation of Directive 2009/81 notwithstanding, not much has changed in relation to offsets. The respondents who believed that changes have occurred described the consequences as largely negative and stated that offset has become less transparent. The European Commission suggests that E.U. member states should employ other means than offset to achieve their security-of-supply requirements. Again, empirical evidence as to the costs and benefits in this connection is not available.

The theoretical case against offsets is a free-trade argument made by scholars such as Martin (1996): countertrade, on account of its bilateral nature, has the effect of reducing trade to the level of the country with the lowest export capacity. Moreover, it runs counter to an open and multilateral system of international trade and is incompatible with the European single market. There are, however, special circumstances wherein countertrade and offsets can be seen as beneficial. These include cases of information asymmetry and other imperfections that render 
market exchange hazardous and inefficient, especially as the technological intensity increases (Taylor 2003), and the existence of oligopolistic distortions in the defence-equipment market may be cited to justify use of industrial policy to achieve a second-best outcome or in an attempt to capture, for domestic citizens, some of the economic rent that such imperfect markets generate (Martin, 1996).

\section{Contracting under an offset sub-contract: An economic approach}

\subsection{The social welfare function}

In the analysis of offsets, the paper builds the logical connections between the offset claimed by the country that is acquiring the arms from the producing country, the process of negotiation on price between the acquiring and delivering country, and the final impact of the trade on the national security of the acquiring country. ${ }^{7}$ All three of these mechanisms are interlinked and essential parts of the analysis. The model highlights the expectation effects of the decisions arrived at in preceding decision stages on the decisions taken at later stages.

In the model world of the paper, there are two countries, $A$ and $B$, and there are two firms: firm $a$ is located in country $A$ and firm $b$ in country $B$. Country $A$ is building its national defence by acquiring $n$ units of arms from the firm in country $B$ via a procurement contract. For the national security, the military capacity $n$ represents a public good and is tax-financed. For the reasons

\footnotetext{
${ }^{7}$ In analytic terms, backward induction must be applied to solve a three-stage decision-negotiation problem. Because the decision process therefore involves expectation mechanisms, the model is quite involved. For this reason and to obtain analytic solutions in various stages, the basic structure is kept as simple as possible. The backward induction procedure guarantees that the solution is time-consistent and that the expectations in the model world are rational.
} 
explained above, country $A$ demands a direct offset transaction from country $B$. A natural interpretation of the offset contract is that the arms might, for instance, be assembled and subsequently serviced in country $A$ over their service life. Servicing is carried out by professionals of country $A$. To highlight the significance of the direct offset, a somewhat extreme view is adopted in the model world that the arms do not function properly without the servicing inputs provided locally by the acquiring country, $A$.

Without loss in generality, both the costs of development and those of production by firm $b$ are normalised to 0 in the model world of this paper. We let variables $p$ and $q$ denote, respectively, the unit value of the defence materiel in the delivery contract and the value of the offset obligation. The resulting offset ratio, $q / p$, is taken to be less than 1 . The net value of the delivery contract hence is $n(p-q)$, where $n$ represents the scale of the contract. ${ }^{8}$

The natural security, $S$, is assumed to be positively related to the scale of the delivery contract, n. It represents a tax-financed public good. Each unit of arms acquired contributes to the national security. The value of the offset transaction, $q$, directly enhances the national security through the insurance effect. ${ }^{9}$ Therefore, it is convenient to let the production function for the national security, $S$, be represented by

\footnotetext{
${ }^{8}$ It is appropriate to read $n$ as a 'mass' instead of a discrete variable. The easiest way to consider the model is to think of $p$ as the gross unit value of, say a fighter as paid by the acquiring country to the delivering country. Then, $q$ can be thought of as the cost paid by the delivering country to the acquiring one for the services produced domestically by the acquiring country. It is the net cost per fighter, $p-q$ multiplied by $n$, that has to be financed by domestic taxes. Many countries try to impose an offset of up to 100 per cent of the delivery contract. However, this is achieved via a 'multiplier' process. Such a procedure is not applied in the case of direct offsets - which can amount to, say, 25 per cent, for example. General knowledge suggests that the associated price premium could amount to, for instance, five per cent.

${ }^{9}$ While formally introducing the operation and servicing uncertainty for the arms materiel acquired is possible, this would complicate the notation unnecessarily without adding insight, so we introduce a more straightforward view that the offset enhances insurance against such risks.
} 


$$
\mathrm{S}=\alpha \mathrm{n}+\beta \mathrm{q}, \quad \alpha>0, \beta>0 .
$$

The $\alpha$ parameter measures the effectiveness of the defence materiel in creation of the national security while $\beta$ denotes the incremental safety provided by the domestic servicing. ${ }^{10}$

We let $\lambda>0$ denote the cost parameter associated with the social cost of public funds. Then the social welfare function serving as a criterion for country $A^{\prime}$ 's decision-making is given by ${ }^{11}$

$$
w=\alpha n+\beta q-\frac{1}{2} \lambda n^{2}(p-q)
$$

The time line of the events in the decision process and the game tree has three stages: 0,1 , and 2 . In stage 0 , country $A$ opens public competitive bidding among producers for the arms that it wants to acquire. Bidding creates an outside option for country $A$ in its relationship with country $B$, enhancing its negotiation power. In stage 0 , country $A$ also announces its (direct) offset obligation, $q$, which it demands from the delivering country. The products available are subject to variation in performance and in quality. The number of competing producers and the relative performance of their products determine the relative bargaining power of country $A$ when it is engaged in price negotiations with one of the producers (say, country $B$ ). The market structure and the process of competing bidding are not explicitly modelled; however, the competitive bidding is assumed to determine the relative bargaining power of country $A$, to be denoted by $0<\theta<1$. Intensive

\footnotetext{
${ }^{10}$ The fact that $n$ is thought of in terms of a quantity and $q$ in terms of a value should not be a great worry, since $q$ at the same time measures the quantity of domestically provided services. ${ }^{11}$ The model's linearity with respect to variables $p$ and $q$ and the quadratic term are introduced to make the model solvable. The expectation effects to be introduced, $\left(\frac{\partial n^{e}}{\partial q}\right),\left(\frac{\partial n^{e}}{\partial p}\right),\left(\frac{\partial p^{e}}{\partial q}\right)$, assist in characterising the internal solutions at each stage of the decision process.
} 
bidding raises country $A$ 's bargaining power. The bargaining power of country $B$ is then denoted by $1-\theta$. The offset requirement chosen will be solved for in stage 0 from the maximisation of its social welfare in anticipation of the forthcoming price bargaining and its subsequent choice of military budget (i.e. the number of arms to be acquired). Then, in the bargaining phase, stage 1 , the offset obligation is given and the negotiation pertains to the price with the assumption that the decision as to how many arms to buy is conditional on the price. In the final phase, stage 2 , the scale of the acquisition is determined.

\subsection{Optimal acquisition of defence materiel}

In the spirit of backward induction, the optimal acquisition in the final stage is solved for first. Carrying out the maximisation for equation 2 with respect to $n$ and regarding offset requirement $q$ and unit price $p$ as predetermined, the solution is

$$
n^{*}=\frac{\alpha}{\lambda(p-q)}
$$

The comparative static effects can be summarised conveniently as

$$
\frac{\partial n^{*}}{\partial p}<0, \frac{\partial n^{*}}{\partial q}>0, \frac{\partial n^{*}}{\partial \lambda}<0, \frac{\partial n^{*}}{\partial \alpha}>0 .
$$

This information is imbedded in Proposition 1: 
Proposition 1. The optimal scale of the acquisition for the buyer is positively related to the efficiency of the arms in creation of national security $(\alpha)$ and to the offset $(q)$. It is negatively related to the social cost of public funds ( $\lambda$ ) and the unit price (p) under the contract.

All these comparative static effects are clear-cut and intuitive. The negative price-sensitivity of the scale of the delivery contract and the offset effect in (4) have to be fed in to the analysis in the previous stages in the decision tree, as analysed in the following sections of the paper. ${ }^{12}$

The result (see equation 3) can be used to establish the security level of country A ex post once the delivery has taken place:

$$
S=\frac{\alpha^{2}}{\lambda(p-q)}+\beta q
$$

This equation highlights the vision advanced by Taylor (2012): offsets definitively have a positive role to play in helping to create and to maintain the national security. There is more to it, though. Inserting equation 3 into equation 1 and evaluating the derivatives, one finds

$$
\begin{aligned}
& \frac{\partial S}{\partial q}=\frac{\alpha^{2}}{\lambda(p-q)^{2}}+\beta>0 \\
& \frac{\partial^{2} S}{\partial q^{2}}=2 \frac{\alpha^{2}}{\lambda} \frac{1}{(p-q)^{3}}>0 .
\end{aligned}
$$

\footnotetext{
${ }^{12}$ Notice that the effectiveness of the offset parameter $\beta$ does not enter (3) directly but interacts with the scale of delivery $n^{*}$ through the price and offset variables $p$ and $q$.
} 
This is an important finding.

Proposition 2. The national security is strictly convex in the offset transaction.

The contribution of the analysis presented here lies in its suggestion that the posited positive function of offsets is based on an insurance mechanism not provided by the insurance markets. The convexity result is important in that it highlights the value of offsets in defence contracts. The result provides an answer to the puzzle as to why the buying countries are so keen to claim offsets in their trading in sophisticated defence materiel.

\subsection{Negotiation of the delivery price}

Knowing the scale of the forthcoming delivery and given the offset requirement, we can now introduce price bargaining between countries $A$ and $B$. A generalised form of Nash bargaining subject to the relative bargaining powers can be stated as ${ }^{13}$

$$
\max _{p} \quad \Gamma=w^{\theta} u^{1-\theta}
$$

where

$$
u=n(p-q)
$$

\footnotetext{
${ }^{13}$ The solution is referred to as a Nash bargaining solution (Nash, 1950; 1953). This is a Pareto efficient solution to a Nash bargaining game. In this game, the solution consists of each player obtaining her status quo payoff (i.e. the non-co-operative payoff) and an additional share of the benefits that arises from co-operation. Many applications of the Nash bargaining process allow for differences in negotiation power. This idea is built from in the model described in the present paper.
} 
is the income of the delivering country from the delivery contract. Recall that the bargaining powers of the parties are denoted by $\theta$ and $1-\theta \cdot{ }^{14}$ Given the assumption that the costs of production are normalised to 0 , the bargaining model (equation 6) assumes that the threat point is $(0,0) .{ }^{15}$ The contract price is determined from

$$
p^{*}=\arg \max _{p} \quad \log \Gamma=\theta \log (w)+(1-\theta) \log (u) .
$$

Function $\log \Gamma$ is continuous for all $p \geq 0$, and it has first and second derivatives in that domain. Its concavity in the price is not an issue, because of the logarithmic transformation. The first-order condition is given by

$$
\theta \frac{w_{p}}{w}+(1-\theta) \frac{u_{p}}{u}=0
$$

In seeking the solution for contract price $p$, the offset claim $(q)$ is considered predetermined from the previous stage while the contracting parties evaluate the effect of the contract price on their expectations of the scale of the delivery contract, $\left(\frac{\partial n}{\partial p}\right)^{e}$. Solving the first-order condition for the unit price reveals that the first-order condition can be evaluated to yield

$$
a(p-q)^{2}+b(p-q)+c=0
$$

\footnotetext{
${ }^{14}$ The relative bargaining power may depend on how many competing producers are active in the market. For instance, with respect to rivals for production of the fighter replacing the F/A-18 Hornet in Finland, publicly available material from the media has considered the U.S.A., Sweden, France, and Eurofighter $\mathrm{GmbH}$ as potential candidates.

${ }^{15}$ As the bargaining process is quite involved, it is appropriate to simplify by working with 0 threat points.
} 
where

$$
\begin{gathered}
a=-\frac{1+\theta}{2(1-\theta)} \lambda n^{2}\left(\frac{\partial n}{\partial p}\right)>0 \\
b=\frac{\theta}{1-\theta}\left(\frac{\partial n}{\partial p}\right) n-\frac{\theta}{1-\theta} \lambda n^{3}+\left(\frac{\partial n}{\partial p}\right)(\alpha n+\beta q)-\frac{1}{2} \lambda n^{3}<0 \\
c=(\alpha n+\beta q)>0 .
\end{gathered}
$$

We can now solve equation (9) for the bargaining price:

$$
p^{*}=q+\frac{-b \pm \sqrt{b^{2}-4 a c}}{2 a}
$$

The solution has to be a real number instead of a complex one; therefore, the parameters of the model have to satisfy the condition $b^{2}-4 a c \geq 0$. The parameter space of the model is rich enough in that combinations of parameters exist that satisfy such a condition. However, there are still two solution candidates given by the two real roots, say $0<p_{1}<p_{2}$. As $-b>0$ and $\sqrt{b^{2}-4 a c}<-b$, it follows that the bargaining process must have one maximum in terms of the negotiation price and one minimum. As

$$
\frac{\partial \log \Gamma}{\partial p}_{\mid p=0}>0
$$


it follows that only the smaller root qualifies as the maximum. ${ }^{16}$

When no offset is claimed, the solution for the bargaining price is given by

$$
p_{\mid q=0}^{*}=\frac{-b-\sqrt{b^{2}-4 a c}}{2 a}>0 \text {. }
$$

It is suggested by (10) that with a positive offset, the bargaining price is fully adjusted to the offset. Therefore, we report the following conclusion:

Proposition 3 (Absence of a free lunch). The offset claim is capitalised in the delivery price.

The capitalisation effect is one of the key findings of our analysis. It has been hinted at by the literature - for instance, in the writings of Eriksson (2007) and Taylor (2012). The work reported on here confirms the validity of such suggestions by deriving a quantitative measure for the price effect in terms of the model above.

To make sure, the result (10) does not represent a closed-form solution for the negotiation price but instead provides an informative characterization of the solution at equilibrium. The reason is that the right-hand side of (10) includes the price variable implicitly through the $a, b$ and $c$ parameters. ${ }^{17}$ Equation (10) suggests in which way the contract price depends on the effectiveness of the defence materiel, the level of bargaining power, the social cost of public

\footnotetext{
${ }^{16}$ The greater root represents the minimum.

${ }^{17}$ Such an approach is typical in other fields of economics - in optimal tax theory in particular.
} 
funds, and the buyer's price-sensitivity: $\left(\frac{\partial n}{\partial p}\right)$. Under given expectations, the effects of exogenous parameters on the negotiation price can be traced by studying their effects on the $a$, $b$, and $c$-parameters. The logic of the model requires that the efficiency of the defence materiel and the offset in sustaining national security increase the willingness to pay a higher bargaining price, $\frac{\partial p}{\partial \alpha}>0, \frac{\partial p}{\partial \beta}>0$. Parameters $b$ and $c$ indeed are positively related to $\alpha$ and $\beta$, and, accordingly, so is bargaining price $p^{*}$ through these parameters. The effects of the other exogenous parameters - bargaining power $\theta$, the cost of public funds $\lambda$, and the price sensitivity of demand $\left(\frac{\partial n}{\partial p}\right)$ - increase the value of $a$, thereby reducing the bargaining price as they should. However, their impact on the $b$ parameter is unclear and makes the price effect somewhat undetermined. In the full rational expectations equilibrium, those effects do not disappear. However, they are somewhat more involved.

The conflict in interests between delivering and acquiring countries shows up in that country $A$ clearly prefers a low price with a more extensive-scale delivery while country $B$ prefers a higher one. Via contracting, efficiency gains are available. The FF frontier in Figure 1 depicts such mutual gains. The bargaining solution is depicted both in the case wherein the bargaining power of the buyer is low $\left(u_{o}, v_{o}\right)$ and in that in which it is high $\left(u^{*}, v^{*}\right)$. 


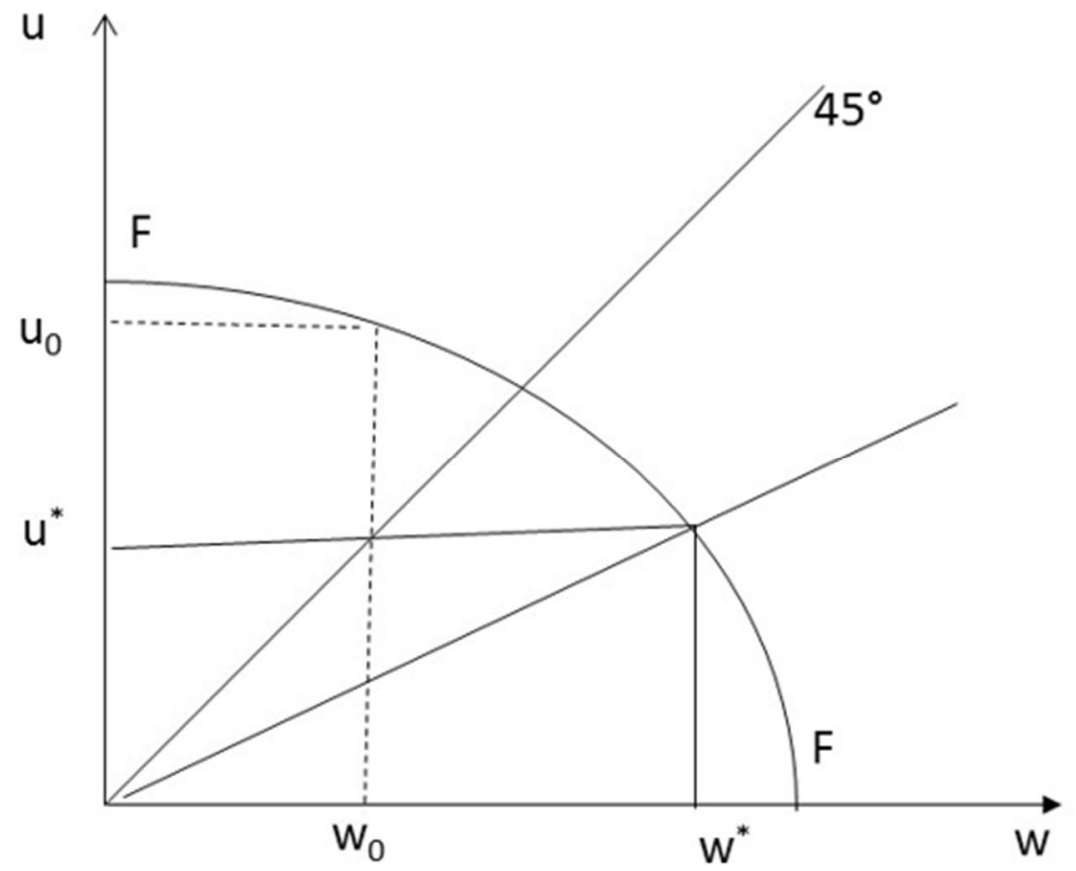

Figure 1. The bargaining solution for the delivery price and the resulting shares of the surplus.

\subsection{The optimal offset claim}

Having solved above for the optimal scale of the delivery and characterised the outcome of the price bargaining, we turn in this section to the final challenge for the analysis, the optimal offset claim. Such analysis has eluded earlier literature. ${ }^{18}$ The task is to characterize the optimal offset by country $A$ in anticipation of the subsequent bargaining process and the coming decision on the scale of the delivery.

The optimal offset claim satisfies

\footnotetext{
${ }^{18}$ It has, however, been suggested by Taylor (2012) that a high optimal offset claim may follow from the Prisoners' Dilemma being acted out by the bidders.
} 


$$
q^{*}=\arg \max \left\{\alpha n^{e}+\beta q-\frac{1}{2} \lambda\left(n^{e}\right)^{2}\left(p^{e}-q\right)\right\} .
$$

As the optimal offset depends on the expectations related to the forthcoming price and the scale of the acquisition, a closed-form solution will not be available. However, a characterisation of the optimal solution is available. The first-order condition for the optimal offset is expressed as the equality between the marginal benefit and the marginal cost of a marginally higher offset claim:

$$
\alpha\left(\frac{\partial n}{\partial q}\right)^{e}+\beta=\lambda\left[\left(n^{e}\right)\left(\frac{\partial n}{\partial q}\right)^{e}\left(p^{e}-q\right)+\frac{1}{2}\left(n^{e}\right)^{2}\left(\left(\frac{\partial p}{\partial q}\right)^{e}-1\right)\right]
$$

The marginal benefit consists of both the direct insurance effect and the indirect effect - i.e. the expected increase in the scale of the delivery contract. The marginal cost too arises from two effects. Firstly, the expected incremental acquisition has to be financed by an additional tax. Secondly, the increase in the offset claim results in tax savings but leads to a response by the deliverer, who demands a higher unit price. The net effect of the latter mechanism is given by the last term:

$$
\left(\frac{\partial p}{\partial q}\right)^{e}-1
$$

We can present the final proposition by way of summary.

Proposition 4. When searching for the optimal offset claim, a country has to balance between the welfare gains arising from the insurance effect and the resulting adverse tax effects as the 
incentive to have a larger-scale acquisition results in increased tax cost. A high social cost of public finance tends to call for a greater offset claim while the incentive to claim a high offset is alleviated when the effectiveness of the delivery and of the offset in the creation of national security are high.

For a formal proof of $\frac{\partial q^{*}}{\partial \lambda}>0$, re-write the first-order condition (13) as a solution for the optimal offset,

$$
q^{*}=p^{e}-\frac{\alpha\left(\frac{\partial n}{\partial q}\right)^{e}+\beta-\frac{1}{2} \lambda\left(n^{e}\right)^{2}\left(\left(\frac{\partial p}{\partial q}\right)^{e}-1\right)}{\lambda\left(n^{e}\right)\left(\frac{\partial n}{\partial q}\right)^{e}}
$$

where $\left(\frac{\partial n}{\partial q}\right)^{e}>0$ and where $\left(\frac{\partial p}{\partial q}\right)^{e}-1=0$ from (10). Then, the above expression offers the prediction that the optimal offset is positively related to the social cost of public funds. Finally, high effectiveness of the delivery, $\alpha$, and of the offset, $\beta$, in the creation of national security alleviate the incentive to claim a high offset.

Is it ever optimal to abstain from an offset claim? Our model-based analysis suggests that it indeed may be. When $\alpha$ is high, the right-hand side of the equation (13) approaches zero. In this case, we can have a corner solution with $q^{*} \leq 0$. Intuitively, the delivery is so important that the country wants to have a large scale without the price effect caused by the offset claim.

Corollary 1. The incentive to claim an offset vanishes altogether when the effectiveness of the delivery in the creation of national security is very high. 


\section{Final remarks}

In this paper, we have suggested a novel view of offsets as an insurance devise. Results were derived for the incidence of the costs of offset contracts between countries that trade in defencerelated materials that are essential for the national defence. The argument presented is new.

The view arising from the analysis offered in this paper suggests that offsets enhance the national security. It was, however, found that to the extent that the cost of the offset contract is capitalised in the price of the delivery contract, the incidence of the requirement of the countertrade contract falls on the buyer. The incidence depends on the valuation of the product to be delivered to the buyer, the negotiation power of the parties making the contract, the social cost of public funds, and the price-sensitivity of the buyer. It has been shown also that the bargaining process results in a unique solution.

The results presented in the paper help to explain why offsets are widely used in procurement contracts for defence materiel. As they contribute to the national security as an insurance mechanism, they should be appreciated by competition laws. An efficient exchange necessitates that the buyer receive what it wants and that the rents for the producer be controlled. Competition in the market for sophisticated arms is imperfect, the trading behaviour is strategic, and the technological skills are differentiated. In these conditions, access to bargaining aids in bringing about efficiency gains for trading partners. 


\section{References:}

Baranowska-Prokop, E. 2009. "Direct offsets in international trade as a remedy for asymmetric information", Journal of International Trade Law and Policy, 8 (3): 202 - 212.

BIS. 2007. Offsets in Defence Trade: 12the Study. U.S. Department of Commerce, Bureau of Industry and Security. USA.

BIS. 2016. Offsets in Defense Trade: 20th Study. U.S. Department of Commerce, Bureau of Industry and Security. USA.

Brauer, J. and J. Dunne. 2011. “Arms trade offsets: what do we know?” In: The handbook on the political economy of war, edited by Coyne, C. J. and R. L. Mathers, 243-268. Cheltenham: Edward Elgar.

Castellacci, F. and A. Fevolden. 2014. "Capable companies or changing markets? Explaining the export performance of firms in the defence industry." Defence and Peace Economics, 25 (6): 549-575.

Caves, R. and D. Marin. 1992. "Countertrade Transactions: Theory and Evidence”, Economic Journal 102 (414): 1171-1183.

Eriksson, E. A., M. Axelson, K. Hartley, M. Mason, A. S. Stenérus, and M. Trybus. 2007. Study on the Effects of Offsets on the Development of a European Defence Industry and Market. Final Report of 06-DIM-022, Brussels: EDA.

European Commission (EC). 2013. Towards a More Competitive and Efficient European Defence and Security Sector. Communication from the commission to the European parliament, the council, the European economic and social committee and the committee of the regions. $\mathrm{COM} / 2013 / 542$. 
European Commission (EC). 2010. Directive 2009/81/EC on the award of contracts in the fields of defence and security - Guidance Note: Offsets. Directorate General Internal Market and $\begin{array}{lllll}\text { Services. } & \text { Accessed } & \text { October } & 23 & 2011 .\end{array}$ http://ec.europa.eu/internal_market/publicprocurement/docs/defence/guide-offsets_en.pdf European Commission (EC). 2016. Evaluation of Directive 2009/81/EC on public procurement in the fields of defence and security Accompanying the document Report from the Commission to the European Parliament and the Council on the implementation of Directive 2009/81/EC on public procurement in the fields of defence and security, to comply with Article 73(2) of that Directive. Commission Staff Working Document. Brussels.

Fevolden, A. M., and K. Tvetbråten. 2016. ’Defence industrial policy-a sound security strategy or an economic fallacy?" Defence Studies, 16 (2): 176-192.

Furter, Denise Lee. 2014. "The Influence of Legislation and Government Policy on Patterns of International Defence Trade and Future Markets: The Case of Offset and Directive 2009/81/EC.” Doctoral Thesis, Brunel University.

GAO. 1997. B-2 Bomber - Cost and Operational Issues. Report to Congressional Committees, United States General Accounting Office, USA. Accessed March 52017. http://www.gao.gov/assets/230/224502.pdf.

Hall, P., and S., Markowski. (1994). "On the Normality and Abnormality of Offset Obligations." Defence and Peace Economics 5 (3): 173-188.

Hennart, J-F. and E. Anderson. 1993. "Countertrade and the Minimization of Transaction Costs: An Empirical Examination“, Journal of Law, Economics \& Organization 9 (2): 290-313. 
Kanniainen, V., and J. Mustonen. 1989. "Balanced trade under uncertainty: A multiperiod noncooperative game approach", European Journal of Political Economy, 5 (1): 113-123.

Korhonen, P. 2011. "Lentokalustohankintojen suorien vastakauppojen toteutus ja kaluston ylläpito lentokaluston keskuskorjaamoilla. [Implementation of direct offsets and maintenance in aircraft procurement at central aircraft maintenance depot]" Doctoral Thesis, University of Tampere.

Martin, S. 1996. "Countertrade and Offsets: An Overview of the Theory and Evidence." In: The Economics of Offsets: Defence Procurement and Countertrade, edited by S. Martin, 15-48. Abingdon: Routledge.

Mirus, R. and B. Y. Yeung. 1986. "Economic Incentives for Countertrade". Journal of International Business Studies 17 (3): 27-39.

Nash, J. 1950. "The Bargaining Problem" Econometrica: Journal of the Econometric Society, 18 (2): $155-162$.

Nash, J. 1953. "Two-Person Cooperative Games" Econometrica Journal of the Econometric Society 21 (1): 128-40.

Petersen, C. D. 2011. "Defense and commercial trade offsets: Impacts on the U.S. industrial base raise economic and national security concerns". Journal of Economic Issues 45 (2): 485491.

Platzgummer, Peter. 2015. "Performance Management in Arms Trade Offsets: The Rationale and Application of Effective Management Tools.” PhD diss. University of St. Gallen.

Schoeni, D. E. 2015. "Second-Best Markets: On The Hidden Efficiency of Defense Offsets". Public Contract Law Journal 44 (3): 369-415. 
Taylor, T.K. 2012. "Countertrade Offsets in International Procurement: Theory and Evidence”, In Designing Public Procurement Policy in Developing Countries, edited by M.A. Yülek and T.K.Taylor, 15-34. New York: Springer.

Taylor, T. K. 2003. "The Proper Use of Offsets in International Procurement", Journal of Public Procurement 3 (3): 338-356.

Ungaro, A.R. 2013. "Trends in the Defence Offsets Market." Paper presented at the $17^{\text {th }}$ Annual International Conference on Economics and Security (ICES), Stockholm, June 14-15.

Yavas, B. F., R. Freedand and D. Vardiabasis. 2000. "Uncertainty, the Lemon Problem, Asymmetric Information and Countertrade: An Economic Perspective", Journal of Transnational Management Development 5 (1): 3-32.

World Trade Organisation (WTO). 1994. Agreement on Government Procurement. Accessed January 222016 https://www.wto.org/english/tratop e/gproc e/gpa 1994 e.htm 